\title{
Study of adaptability and efficacy of menstrual cup in managing menstrual health and hygiene
}

\author{
C. R. Kakani, Jalpa K. Bhatt*
}

Department of Obstetrics and Gynecology, Dr. M. K. Shah Medical College and Research Centre, Chandkheda, Ahmedabad, Gujarat, India

Received: 04 May 2017

Accepted: 29 May 2017

*Correspondence:

Dr. Jalpa K. Bhatt,

E-mail: drjalpavyas@yahoo.com

Copyright: (c) the author(s), publisher and licensee Medip Academy. This is an open-access article distributed under the terms of the Creative Commons Attribution Non-Commercial License, which permits unrestricted non-commercial use, distribution, and reproduction in any medium, provided the original work is properly cited.

\section{ABSTRACT}

Background: Menstrual cups have been available for decades, but their use is limited by bulky design and the need for multiple sizes. However, some benefits have been reported like improvement in managing health and hygiene during menstruation, better information on the average menstrual fluid discharged by women during menstruation and attainment of more knowledge bridging the lacuna in knowledge about the adaptability and efficacy of menstrual cup as a better alternative to conventional options. The study is aimed towards assessing the adaptability and the effectiveness of menstrual cup by naïve users who have been using sanitary pads/tampons/cloth as conventional menstrual sanitary protection.

Methods: The study was conducted at conducted Gujarat Medical Education and Research Society, Medical College and Hospital, Dharpur, Patan, Gujarat, India. Total 158 participants aged between ages of 20 to 50 years with regular menstrual cycle were enrolled in the study. Participants were provided menstrual cups to be used for three consecutive menstrual cycles. They were given detailed explanation/information about its usage. Feedback was obtained after every cycle for three cycles using a structured questionnaire.

Results: The cup was preferred for comfort, dryness, and less odor. Insertion was easy for $80 \%$ participants and $90 \%$ participants found removal easy. Problem of leakage was encountered in 3-6\%. There were few side effects like rashes, dryness or infection.

Conclusions: These results demonstrate that this reusable vaginal device has no significant health risks and is acceptable to many women without the need for fitting or other medical services.

Keywords: Adaptability, Effectiveness, Menstrual hygiene, Menstrual cup

\section{INTRODUCTION}

Menstruation is a physiological phenomenon. However, it has been linked to many religious traditions and taboos in developing countries like India. Cultural, religious and traditional beliefs can lead to different restrictions that women face during their menstrual period. The taboos associated with menstruation are not just of historical interest. It is still common for menstruating women to remain isolated at home during the menstrual period. Some of them do not wash their bodies, shower or bathe. In some communities, they are not allowed to use water sources during menstruation as considered unclean. Menstrual management is still a source of social embarrassment, with such euphemisms as time of the month, period, or on the rag still in common use. Even advertisers are still reluctant to talk directly about menstruation; they continue to discuss feminine hygiene 
and urge women to stay fresh. This persistent discomfort with the reality of menstruation is aptly called the culture of concealment by Karen Houppert. ${ }^{1}$

In the developing world, menstrual management is not only difficult; it also may have serious adverse impact on the lives of women. Even when taboos are not a major problem, convenient or inexpensive menstrual collection materials may simply not be available. Efforts to produce inexpensive materials are solely lacking. ${ }^{2}$ Women use cloths, absorbent pads or tampons to manage menstrual flow. Washing the clothes or disposing the pads hygienically is a challenge for most of the females. In many cultures, women resort to the use of rags, which must be reused, but washing them may be limited by lack of water or the privacy needed to wash and reuse pads, resulting in forced use of damp or even wet contaminated rags. ${ }^{2-4}$ A study conducted in October 2010 by A. C. Nielsen called Sanitation Protection: Every Woman Health Right provides in-depth analysis of the prevalent unhygienic practices in India. The survey covered 1033 woman in the menstrual age and 151 gynecologists who studied them. The survey result say that $12 \%$ women use sanitary napkins and rest $88 \%$ women use home based shocking alternatives. ${ }^{5}$ Such unhygienic practice can result in acquiring infection of lower genital tract. Furthermore, in India very less exposure is given towards this subject and is usually neglected. Menstruation can be a barrier to education for many girls, as a lack of effective sanitary products restricts girls' involvement in educational and social activities. ${ }^{6,7}$ Often they do not attend school due to fear of leaking, embarrassment, pain or inadequate sanitation facilities that do not allow them to wash or change in privacy. ${ }^{8}$

Menstrual cup is a device for menstrual flow management and is claimed to be a health and environment friendly alternative to the conventional menstrual sanitary protections. Vaginal devices have a long and intriguing history. In the United States, the first device was patented in $1867 .{ }^{9}$ Early vaginal cups used specifically for menstrual collection have never achieved widespread use, even though they have been available in developed countries for many decades.

Reusable menstrual products (including menstrual cups) are more economical than disposable ones. The menstrual cup has been explored as a means of menstrual hygiene management in developing countries like India. ${ }^{10}$ It is manufactured using health-grade non-toxic non-allergic silicone. As it is made of silicone it is absolutely inert and smooth thereby almost nullifying the problems like infections, allergies, rashes, and excoriations. It is worn internally hence it eliminates foul odour and feeling of wetness. It can also be worn for long hours because of its capacity and the ability to adapt to the body completely. Menstrual cup can be sterilized/autoclaved before use and thus is most hygienic and safe menstrual sanitary protection. It is a reusable device which can last through the menstrual life-cycle of a woman if used carefully.
There are a few clinical studies proving the actual benefits of menstrual cups and thus there is a lot to be proven and confirmed. Hence it leaves a scope for study to evaluate the menstrual cup as an alternative vis-a-vis conventional menstrual sanitary protections in terms of adaptability and efficacy for the user.

\section{METHODS}

This study was conducted Gujarat Medical Education and Research Society, Medical College and Hospital, Dharpur, Patan of Gujarat State in India. It is a tertiary care teaching hospital catering healthcare needs of urban as well as rural areas in the vicinity. Prior written approval of the institutional ethics committee was obtained. Total 158 participants were enrolled in the study conducted over three months. The study was conducted as per ICMR and Helsinki ethical guidelines.

\section{Inclusion criteria}

- Married Menstruating women educated at least up to high school.

- In the age group of 21 to 50 years

- Having regular menstrual cycles

- Using Sanitary Pads/Tampons/Cloth as menstrual sanitary protection

\section{Exclusion criteria}

- Women planning pregnancy within 6 months following the date of the commencement of the study

- Women allergic or sensitive to Silicone

- Women having active vaginal/urogenital infections

- Who do not understand the nature/purpose of the study

The device- the menstrual cup we utilized for the study is an internally worn device with a pliable rim $44 \mathrm{~mm}$ in diameter and a thin-walled reservoir to collect and hold the menstrual fluid. It was designed to minimize bulk in order to facilitate insertion and removal. Once inserted; it opens to an oval shape, positioned between the posterior fornix and the notch behind the pubic bone, covering the cervix. Removal is accomplished by hooking a finger over the rim behind the pubic bone. It is made up of health grade non-toxic non- allergic silicon.

Women fulfilling inclusion criteria were given detailed explanation/information about menstrual cups and the study. Any queries regarding the use of menstrual cup were discussed and solved by personal interview with the women. If they agreed to participate in the study they were requested to sign a written consent form. To collect personal and menstruation related information a predesigned questionnaire was administered through personal interview with respondent. (Annexure I) The participants were provided with the menstrual cup to be used for three consecutive menstrual cycles and report to 
investigators after completion of each menstrual cycle. At every visit participant was interviewed for the perceptions and experience with the help of the questionnaire. Questionnaire included the questions regarding method of wearing, removing, feel and cleansing of the menstrual cup (Annexure II) The questionnaire was filled by the respondents after every cycle (total 3). At every visit, any problems related to use of cup like difficulty in insertion and removal, leakage or any other discomfort were noted and rectified. Conclusive questions were asked to the respondents if the menstrual cup could be used as an effective alternative to other methods and whether it has any advantages over them. Data was analyzed using MS excel 2007.

\section{RESULTS}

At the beginning of the study, 158 participants were enrolled in the study. There were 8 discontinuations, out of which 6 were after first cycle and 2 after second cycle. Discontinuations were due to different reasons like feeling messy (2 participants), could not insert the cup after repeated attempts (2 participants), difficult removal (2 participants), moved out of town (1 participant), and lost to follow up (1 participant). So, total 150 participants were assessed. Equal numbers of participants (70) were in 20 to 29 years and 30 to 39 years age group respectively. Ten participants were in 40 to 50 years age group. Maximum $(66.66 \%)$ participants were multigravida, $26.66 \%$ were primigravida and $6.66 \%$ were nulligravida. Twenty $(13.33 \%)$ participants were having problem of heavy menstrual bleeding, rest of them were having normal cycles.

At the time of entry in the study, $80(53.33 \%)$ women were using cloths and the rest were using sanitary napkins or tampons for menstrual protection. Only $30 \%$ (45) were satisfied with their current method of menstrual sanitary protection. They were particularly dissatisfied with the performance of their current method during overnight wear, when exercising (running, jogging etc) in certain clothes and when busy at work (Table 1).

Table 1: Participant characteristics $(n=150)$.

\begin{tabular}{|c|c|c|}
\hline Characteristic & Group & No. $(\%)$ \\
\hline \multirow{3}{*}{ Age (years) } & 20 to 29 & $70(46.66)$ \\
\hline & 30 to 39 & $70(46.66)$ \\
\hline & 40 to 50 & $10(6.66)$ \\
\hline \multirow{3}{*}{ Gravida } & Nulligravida & $10(6.66)$ \\
\hline & Primigravida & $40(26.66)$ \\
\hline & Multigravida & $100(66.66)$ \\
\hline \multirow{2}{*}{ Menstrual history } & Normal bleeding & $130(86.66)$ \\
\hline & Heavy bleeding* & $20(13.33)$ \\
\hline \multirow{3}{*}{ Menstrual sanitary method } & Clothes & $80(53.33)$ \\
\hline & Sanitary napkins & $65(43.33)$ \\
\hline & Tampons & $5(3.33)$ \\
\hline \multirow{3}{*}{$\begin{array}{l}\text { Income spent on buying the sanitary protection product in a year } \\
\text { (average) in INR }\end{array}$} & $<500$ & $80(53.33)$ \\
\hline & $500-1500$ & $50(33.33)$ \\
\hline & $>1500$ & $20(13.33)$ \\
\hline \multirow{2}{*}{ Level of satisfaction with current method } & Satisfied & $45(30)$ \\
\hline & Dissatisfied & $105(70)$ \\
\hline
\end{tabular}

*Based on number of sanitary protection products consumed per day $(>3)$

Out of $150,120(80 \%)$ women found it easy to wear the cup in first cycle, $125(83.33 \%)$ in second cycle and 135 $(90.11 \%)$ in third cycle. Difficulty was encountered due to improper technique of insertion (5), fear (15) and embarrassment (15). For removal, 135 (90\%) found it easy in first cycle, the comfort levels increased in second $140(93.33 \%)$ and third $142(93.66 \%)$ cycle. For the perception of how it feels, $120(80 \%)$ were comfortable whereas $30(20 \%)$ females were uncomfortable in first cycle. $132(88 \%)$ were comfortable in second cycle and $18(12 \%)$ were uncomfortable. in the third cycle1 40 $(93.33 \%)$ were comfortable and 10 (6.66\%) were uncomfortable. Leakage was encountered in $10(6.66 \%)$ in first cycle which was corrected by proper counselling and advising frequent emptying of cup leading to fall in incidence of leakage in second cycle $8(5.33 \%)$ and third cycle $5(3.33 \%)$. This problem could not be rectified in 2 out of 20 participants who had reported menorrhagia at the time of entry. There were few side effects like rashes in 2 participants, dryness in 3 participants and fungal or bacterial infection in 2 in first cycle. In second cycle dryness was observed in 2 and 1 had infection. In third cycle 1 participant had allergy. All problems disappeared with appropriate treatment (Table 2). Women preferred the cup to their usual method of sanitary protection in comfort, dryness/irritation, odor, length of wear, and 
interference with various activities. Frequent removal (23 times a day) for cleaning the cup was comfortable for $80 \%$ of participants. The overall experience of participants about using menstrual cup over their pervious method of sanitation was satisfactory in $90 \%$ (135).

Table 2: Participant feedback after each cycle.

\begin{tabular}{|c|c|c|c|c|c|c|c|c|c|}
\hline \multicolumn{4}{|l|}{ Cycle 1} & \multicolumn{3}{|l|}{ Cycle 2} & \multicolumn{3}{|l|}{ Cycle 3} \\
\hline & Easy & $\begin{array}{l}\text { Not so } \\
\text { easy }\end{array}$ & Difficult & Easy & $\begin{array}{l}\text { Not } \\
\text { so easy }\end{array}$ & Difficult & Easy & $\begin{array}{l}\text { Not so } \\
\text { easy }\end{array}$ & Difficult \\
\hline Wearing & $\begin{array}{l}120 \\
(80 \%)\end{array}$ & $\begin{array}{l}20 \\
(13.33 \%)\end{array}$ & $\begin{array}{l}10 \\
(6.66 \%)\end{array}$ & $\begin{array}{l}125 \\
(83.33 \%)\end{array}$ & $\begin{array}{l}20 \\
(13.33 \%)\end{array}$ & $\begin{array}{l}5 \\
(3.33 \%)\end{array}$ & $\begin{array}{l}135 \\
(90.11 \%)\end{array}$ & $\begin{array}{l}10 \\
(6.66 \%)\end{array}$ & $\begin{array}{l}5 \\
(3.33 \%)\end{array}$ \\
\hline Removal & $135(90 \%)$ & $\begin{array}{l}10 \\
(6.66 \%)\end{array}$ & $\begin{array}{l}5 \\
(3.33 \%)\end{array}$ & $\begin{array}{l}140 \\
(93.33 \%)\end{array}$ & $\begin{array}{l}8 \\
(5.33 \%)\end{array}$ & $\begin{array}{l}2 \\
(1.33 \%)\end{array}$ & $\begin{array}{l}142 \\
(93.66 \%)\end{array}$ & $6(4 \%)$ & $\begin{array}{l}2 \\
(1.33 \%)\end{array}$ \\
\hline Feel & Comfortable & $\begin{array}{l}\text { Uncom- } \\
\text { fortable }\end{array}$ & & Comfortable & $\begin{array}{l}\text { Uncom- } \\
\text { fortable }\end{array}$ & & Comfortable & $\begin{array}{l}\text { Uncom- } \\
\text { fortable }\end{array}$ & \\
\hline & $\begin{array}{l}120 \\
(80 \%)\end{array}$ & $\begin{array}{l}30 \\
(20 \%)\end{array}$ & & $\begin{array}{l}132 \\
(88 \%)\end{array}$ & $\begin{array}{l}18 \\
(12 \%)\end{array}$ & & $\begin{array}{l}140 \\
(93.33 \%)\end{array}$ & $\begin{array}{l}10 \\
(6.66 \%)\end{array}$ & \\
\hline Leakage & Yes & No & & Yes & No & & Yes & No & \\
\hline & $\begin{array}{l}10 \\
(6.66 \%)\end{array}$ & $\begin{array}{l}140 \\
(93.33 \%)\end{array}$ & & $\begin{array}{l}8 \\
(5.33 \%)\end{array}$ & $\begin{array}{l}142 \\
(94.66 \%)\end{array}$ & & $\begin{array}{l}5 \\
(3.33 \%)\end{array}$ & $\begin{array}{l}145 \\
(96.66 \%)\end{array}$ & \\
\hline Cleaning & Easy & Difficult & & Easy & Difficult & & Easy & Difficult & \\
\hline & $135(90 \%)$ & $\begin{array}{l}15 \\
(10 \%)\end{array}$ & & $\begin{array}{l}136 \\
(90.66 \%)\end{array}$ & $\begin{array}{l}14 \\
(9.33 \%)\end{array}$ & & $\begin{array}{l}137 \\
(91.33 \%)\end{array}$ & $\begin{array}{l}13 \\
(8.66 \%)\end{array}$ & \\
\hline Problems & Yes & No & & Yes & No & & Yes & No & \\
\hline Allergy & 0 & 0 & & 0 & 0 & & $1(1.33 \%)$ & - & \\
\hline Rash & $2(1.33 \%)$ & - & & 0 & - & & 0 & 0 & \\
\hline Dryness & $3(2.00 \%)$ & - & & $2(1.33 \%)$ & - & & 0 & 0 & \\
\hline Infection & $2(1.33 \%)$ & - & & $1(0.66 \%)$ & - & & 0 & 0 & \\
\hline
\end{tabular}

\section{DISCUSSION}

More than $80 \%$ of participants found menstrual cup insertion easy with increasing comfort in second and third cycle mostly due to help of spouse and previous experience. Removal was easy in $90 \%$ of participants. Difficulty in removal was due to scanty periods, dryness of vagina and discomfort by contact with menstrual fluid. The concerns about messy removal and inconvenient disposal might be minimized by including an inexpensive plastic glove with the cup packaging.

There was minimal problem of leakage. Those who did experience leakage rated it as equivalent to leakage with their prior method. High comfort levels were accounted to medical graded silicon rubber material. Most participants did not find any problem in cleaning the cup in all the three cycles as teaching for cleaning with soap and water was part of counselling. Those who found difficulty were due to non-availability of sanitation facilities and privacy. The problems of rashes, dryness, infection and allergy were minimal and managed appropriately. The menstrual cup was acceptable to most users in relation to comfort, ease of use, and effectiveness in menstrual collection. Cited advantages include overall convenience, portability and easy storage, extended wear time, and greater freedom of movement. ${ }^{11,12}$ When reusable, menstrual cups are easy to clean and, therefore, more hygienic than cloth pads, and they require less water for cleansing. ${ }^{12}$ Internal placement of cups avoids the odor and discomfort of an external pad. Reusable menstrual cups have an economic advantage..$^{2,13-15}$ Overall, women preferred the cup to their current method of menstrual management.

There are relatively few study reports that evaluate safety and acceptability of cups with actual use during menses. In 1962, Karnaky evaluated 50 women using a bellshaped cup. ${ }^{16}$ A 1995 study of 52 Canadian women found menstrual cup was acceptable to $45 \%$ after 2 to 12 cycles of use. ${ }^{17} \mathrm{~A}$ recent report describes acceptability of a menstrual cup among adolescent school girls in Nepal. ${ }^{12}$ This study reports rapid adoption of cup use, with $60 \%$ using cups by 6 months and continuing use for the length of the study. We have excluded adolescent school girls keeping in mind the virginity issue. A study from Zimbabwe reported that all women surveyed $(n=43)$ would definitely try a menstrual cup, and $86 \%$ reported that using it would make a difference in their lives. ${ }^{18} \mathrm{We}$ found higher acceptance compared to previous studies due to detailed counseling before enrollment. Moreover, we enrolled only those women who were ready and consented voluntarily to participate in the study. During the study at every follow up visit, attempts were made to 
resolve any problems related to use of menstrual cup by counseling again. Limitations of our study are short duration and lack of following the participants after conclusion of study.

Clearly, a major barrier to menstrual cup acceptance is the requirement that the menstrual cup be manipulated into and out of the vaginal vault, necessitating contract with genital tissues and with menstrual fluid. Obviously, women who are uncomfortable, mostly with this aspect of menstrual cup use. ${ }^{19}$ This problem can be overcome by proper counseling of the users regarding its use. There is no device to collect the menstrual blood for a quantitative analysis of blood loss during menstruation which again is a big gap in learning. Menstrual cups are also the best way to make a quantitative assessment of the menstrual blood loss as it is a menstrual fluid collector unlike other menstrual sanitary protections like Pads/Tampons/Cloth which are absorbents.

\section{CONCLUSION}

In spite of the limitations of this study, this study shows that the menstrual cups can replace the current methods of menstrual sanitation due to lower cost and improved hygiene. Increasing awareness and easy availability of this product can help in increasing the use. Government agencies can take help of female health workers to increase the awareness and assist the use of this device and thus improving the menstrual hygiene at lower cost which will be of significant importance in developing countries like India. It could be concluded that menstrual cups could be an eco-friendly option in comparison to other used vaginal devices which have great disposal problems. Adequate sanitation facilities and menstrual hygiene products are just one part of the solution to impeding women's progress in many developing countries.

Funding: No funding sources

Conflict of interest: None declared

Ethical approval: The study was approved by the Institutional Ethics Committee

\section{REFERENCES}

1. Houppert K. The curse: Confronting the last unmentionable taboo: Menstruation. Macmillan;1999.

2. Bharadwaj S, Patkar A. Menstrual hygiene and management in developing countries: Taking stock. Mumbai: Junction Social. 2004.

3. Ten VTA. Menstrual hygiene: A neglected condition for the achievement of several millennium development goals. Europe External Policy Advisors. 2007.

4. Delaney J, Lupton MJ, Toth E. The curse: A cultural history of menstruation. University of Illinois Press; 1988.

5. Nilesen AC. Sanitary Protection: Every Woman's Health Right. a survey undertaken. Reviewed and endorsed by community development organization Plan India, the survey was conducted in October 2010 and involved 1,033 women in the menstrual age and 151 gynaecologists from across India. 2011.

6. Puberty education and menstrual hygiene management good policy and practice in health education - Booklet 9. United Nations Educational, Scientific and Cultural Organization (UNESCO);2014. Available at: http://unesdoc.unesco.org/images/0022/002267/226792 e.pdf

7. Montgomery P, Ryus CR, Dolan CS, Dopson S, Scott LM. Sanitary pad interventions for girls' education in Ghana: a pilot study. PloS one. 2012;7(10):e48274.

8. Crofts T. Menstruation hygiene management for schoolgirls in low-income countries. Loughborough, UK, Water, Engineering and Development Centre (WEDC). 2012.

9. Hockert SL. Catamenial Sack. U.S. Patent and Trademark Office. 1867. Patent No. 70843.

10. van Eijk AM, Sivakami M, Thakkar MB, Bauman A, Laserson KF, Coates $\mathrm{S}$ et al. Menstrual hygiene management among adolescent girls in India: a systematic review and meta-analysis. BMJ open. 2016;6(3):e010290.

11. Liswood R. Internal menstrual protection. Use of a safe and sanitary menstrual cup. Obstet Gynecol. 1959;13:539-43.

12. Oster EFT. Thornton RE. Menstruation and education in Nepal. National Bureau of Economic Research Working Paper Series. 2009; 14853.

13. Wysocki S. New options in menstrual protection. A guide for nurse practitioners. Adv Nurse Pract. 1997;5:51-4.

14. Stewart K. Powell M. Greer R. An alternative to conventional sanitary protection: Would women use a menstrual cup? J Obstet Gynecol. 2009;29:49-52.

15. van der Straten A, Sahin-Hodoglugil N, Mtetwa S. Feasibility and acceptability of cervical barriers among vulnerable youth: A pilot study in Zimbabwe. 4th IAS Conference on HIV Pathogenesis, Treatment, and Prevention; Sydney, Australia. 2007.

16. Karnaky K. Internal menstrual protection with the rubber menstrual cup. Obstet Gynecol. 1962;19:688-91.

17. United States Pharmacopoeia. Classification of plastics (Class VI) testing, USP XXII. 1990:1497-500.

18. Averbach S, Sahin-Hodoglugil N, Musara P. Chipato T. van der Straten A. Duet ${ }^{\circledR}$ for menstrual protection: A feasibility study in Zimbabwe. Contraception. 2009; 79:463-8

19. North BB, Oldham MJ. Preclinical, clinical, and overthe-counter postmarketing experience with a new vaginal cup: menstrual collection. J Women's Health. 2011;20(2):303-11.

Cite this article as: Kakani CR, Bhatt JK. Study of adaptability and efficacy of menstrual cup in managing menstrual health and hygiene. Int J Reprod Contracept Obstet Gynecol 2017;6:3045-53. 


\section{Annexure}

Annexure I: Respondents feedback form: (please tick as applicable and write if required)

CYCLE-
Ending $\ldots \ldots \ldots \ldots \ldots \ldots \ldots \ldots \ldots \ldots \ldots \ldots \ldots \ldots \ldots \ldots \ldots \ldots \ldots \ldots \ldots \ldots$

1) Ease of Wearing:

Easy $\bigcirc \quad$ Not so easy $\bigcirc \quad$ Difficult $\bigcirc$

Removal:

Easy $\bigcirc \quad$ Not so easy $\bigcirc \quad$ Difficult $\bigcirc$

2) Feel:

Comfortable $\bigcirc \quad$ Uncomfortable $\bigcirc$

3) Leakage:

No leakage $\bigcirc \quad$ Leakage $\bigcirc$

4) Cleaning:

Easy $\bigcirc \quad$ Difficult $\bigcirc$

5) Menstrual odour:

No odour $\bigcirc \quad$ Odour $\bigcirc$

6) Did you have any of the following problems after using the menstrual cup:
Allergy $\bigcirc$
Rashes/Irritation $\bigcirc$
Vaginal infection $\bigcirc$
Dryness $\bigcirc$

TSS (Toxic Shock Syndrome) $\bigcirc$

Others:

7) Quantity of menstrual fluid:

8) What extra activities you can do using the cup freely which you were hesitant wearing sanitary napkins/ Tampons/Cloth :

Sleeping comfortably at night $\bigcirc \quad$ Sports activities like running jogging etc. $\bigcirc$

Swimming $\bigcirc$

Others

9) How frequently do you need to remove the cup and clean it in menstrual days:
1-2 times a day
2-3 times a day
More than 3 times a day $\bigcirc$

OVERALL experience:

Excellent $\bigcirc \quad$ Good $\bigcirc \quad$ Average $\bigcirc \quad$ Bad $\bigcirc$

ANY SUGGESTIONS TO IMPROVISE THE PRODUCT: 
Annexure II: Respondent information form: (please tick as applicable and write if required) 1)Name (optional) :

First name:

Last name:

2) Age

Below $20 \bigcirc$ 20-30

$30-40 \bigcirc$

above $40 \bigcirc$

3) Marital status

Married $\bigcirc$

Unmarried $\bigcirc$

4) Qualification

Matriculate but undergraduat $\mathrm{e} \bigcirc$

Graduate $\bigcirc$

Post graduate $\bigcirc$

5) Work occupation

Housewife $\bigcirc$ Self-employed

Service $\bigcirc$

6) Monthly household income

Above $50000 \bigcirc 25000-50000 \bigcirc \quad$ Below $25000 \bigcirc$

7) Which sanitary protection were you using before menstrual cup

Sanitary pads $\bigcirc \quad$ Tampons $\bigcirc \quad$ Cloth $\bigcirc$

Others:

8) Method adopted by you for disposing the used sanitary product

9) How frequently you change the sanitary protection product in a day(average)
Once $\bigcirc$ Twice $\bigcirc$
Thrice $\bigcirc$
More than 3 times $\bigcirc$

10) How much income is spend on buying the sanitary protection product in a year(average)

Below Rs.500 $\bigcirc$ Rs.500-1500 $\bigcirc \quad$ More than Rs. $1500 \bigcirc$ 


\section{Annexure III: Menstrual cup - user instruction manual.}

\section{Steps to use menstrual cup}

\begin{tabular}{|l|l|}
\hline Knob & You need to hold menstrual cup with clean hands. \\
\hline
\end{tabular}

\section{How to wear menstrual cup?}

There are a variety of positions you can try to comfortably wear the menstrual cup. Some women find it better to squat; others prefer it in the shower.

Try to wear it in a smooth manner and as fast as you can - the more hesitation you have the more difficult it will be as the menstrual cup will keep opening up too soon. Practice, making the unfamiliar familiar, will help a lot. Soon you will be doing it in seconds!

Aim towards the bottom of your spine. The vaginal canal is not vertical or horizontal, it slopes upwards. If you are not familiar with the slope of your canal, try it with a finger to see in what direction you should be inserting.

You only need to push the menstrual cup in as far enough so that the knob remains outside the entrance of your vagina. 


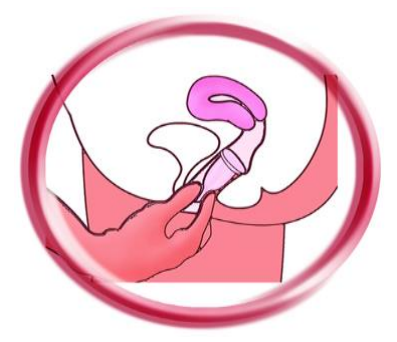

Before wearing the cup

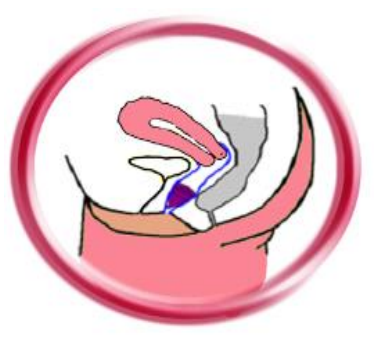

After wearing the cup

\section{How to check after wearing?}

You should feel the menstrual cup unfold inside as soon as you have pushed it in. Some women find it is better to let cup unfold when it is just inside, and then to push it slightly further in - this creates a gentle "suction" which means there will be no leakage. If your cup does not unfold, try relaxing your pelvic muscles and using your index finger to check around the sides of the inserted cup. It may be necessary to give menstrual cup a gentle turn in order to create the seal.

Your menstrual cup should not be as far in as you would push a tampon.

Your menstrual cup should not be touching your cervix.

Properly worn, you should not be able to feel your menstrual cup at all.

\section{How to remove menstrual cup?}

Wash your hands thoroughly with warm/cold water and soap. Take any of the following comfortable position:

- Standing

- Sitting on the toilet

- Squatting

Insert your thumb and index finger to reach the knob; Slide upwards and pinch the base of the cup firmly; Squeeze the cup gently and remove it by tilting it sideways to release the air; Empty the contents into the toilet and wash the cup with menstrual cup wipe provided along with it.

\section{How to clean menstrual cup?}

\section{During the menstrual cycle}

Wash menstrual cup with hot/cold water; Take menstrual cup wipe with a dry hand; Wash menstrual cup with menstrual cup wipe to get a rich lather; Rinse it well to clean it thoroughly.

\section{Beginning and end of the menstrual cycle:}

Boil menstrual cup for twenty (20) minutes in water to sterilize it.

\section{In emergency/trave}

If the sterilization of menstrual cup (20 minutes) is not possible, ensure to clean it thoroughly as per directions before use.

\section{How to Store menstrual cup?}

At the end of your cycle, wash, sterilize, dry and store the menstrual cup in the cotton draw string bag provided. Do not store it in a plastic bag or an air tight container. 